УАK 34:316.014

ББК $67+60.504 / 506$

DOI 10.22394/1682-2358-2018-3-89-95

M.S. Kozlova, Candidate of Sciences (Sociology), Director of the Center for Senior Executives' Reserve Training, Povolzbsky Institute of Management named after P.A. Stolypin, Branch of the Russian Presidential Academy of National Economy and Public Administration

S.V. Kurganova, Candidate of Sciences (Sociology), Docent of the Sociology of Social Work Department, Saratov State University named after N.G. Chernyshevsky

\section{LEGAL PRACTICES OF MODERN URBAN COMMUNITIES: EXEMPLIFIED BY RESIDENTS OF SARATOV}

This article represents the results of the social survey dedicated to legal practices of urban population. In the course of the analysis, such issues as population's orientation to legal ways of problem solution and identification of problem areas in which the population are more likely to turn for assistance of a lawyer are raised.

Key words and word-combinations: legal practices, urban population, social survey.
М.С. Козлова, кандидат соииолоических наук, директор иентра подготовки резерва управленческих кадров Поволжского института утравления имени П.А. Стольтина - филиала Российской академии народного хозяйства и государственной службь при Президенте РФ (етаil: kmargos@yandex.ru)

С.В. Курганова, кандидат соииологических наук, дочент кафедрь сочиологи сочиальной работь Саратовского национального исследовательского государственного университета имени Н.Г. Чернопшевского (email: kurganovasv@ gmail.com)

\section{ПРАВОВЫЕ ПРАКТИКИ СОВРЕМЕННЫХ ГОРОЖАН (на примере жителей Саратова)}

Аннотация. Представляются результаты социологического опроса, посвященного правовым практикам городского населения. В ходе анализа затрагиваются такие вопросы, как ориентация населения на правовые способы решения проблем и выявление проблемных областей, в которых население с большей готовностью обращается за помощью к профессиональному юристу.

Ключевые слова и словосочетания: правовые практики, городское население, социологический опрос.

\section{$\mathrm{H}$} современном российском обшестве все еше остается острой проблемой, находящейся в тесной взаимосвязи со многими Аругими не менее змободневными вопросами - массо- 
вой бедностью, теневыми экономическими практиками, коррупцией и т.А. Об этом пишут в разных аспектах российские исследователи. Так, А.В. Куликова утверждает: «Правосознание большинства россиян характеризуется доминированием размытых представлений о праве, правовой сфере, недоверием к учреждениям права...» [1]. В.Р. Петров, характеризуя российское общество в XXI в., отмечает деформацию правосознания граждан и объясняет ее глубоким реформированием политических, экономических, Ауховных и организационных основ жкизни общества [2]. С.И. Карпушкин вылеляет несколько характерных особенностей отечественной правовой культуры: неустойчивость ценностно-мировоззренческих ориентиров; правовой нигилизм; отсутствие Аоверия к органам государственной власти [3]. Э.М. Амиаярова рассматривает проблемы правовой информированности общества, факторы, влияющие на уровень правовой грамотности гражданина, и подтверждает сделанные вывоАы результатами собственных эмпирических исследований [4] .

Очередному витку внимания исследователей к правовой культуре россиян в текущем десятилетии способствовала и официальная позиция государственной власти: в мае 2011 г. Президент РФ утвердиц Основы государственной политики Российской ФеАерации в сфере развития правовой грамотности и правосознания граждан, сушественное внимание в которых уделено не только работе правоохранительных, законодательных, судебных органов, но и такому аспекту, как «...Аоступность Аля граждан квалифицированной юридической помощи; неукоснительное соблюдение адвокатами и нотариусами, иными частнопрактикующими юристами в их профессиональной деятельности норм закона и профессиональной этики...» [5].

При изучении особенностей правосознания и правовых установок российского населения с помощью эмпирических исследований неАостаточное внимание, на наш взгляд, уделяется правовой грамотности населения, восприятию им правовой сферы в целом и конкретных правовых ситуаций в частности, особенностям взаимодействия граждан с учреждениями права. Тем не менее ситуаџия постепенно изменяется: формируется правовая куиьтура и распространяются правовые практики в сфере реацьного применения. «Бум» по открытию юридических специальностей в вузах, наблюдавшийся в России в нумевые годы, привел к перенасышению рынка юристов. Появияось множество конкурирующих юридических фирм, предлагающих свои услуги и организациям, и населению. Вместе с тем это явцяется неизбежным сопровождением процесса формирования и развития рыночных структур, института частной собственности, преАпринимательства, потребительской активности и многого Аругого. Медленно, но неуклонно население подАается этим воздействиям, привыкая и принимая необходимость взаимодействия с профессиональными юристами в решении проблем, на необходимость чего указывает один из региональных исследователей, объясняя это сопряженными процессами реформирования судебно-правовой, административной систем [6] .

Какие направления юридической поддержки оказались «фмагманами» спроса со стороны саратовцев? В каких случаях граждане готовы обращаться за помощью к профессионалам в мире права? Какой информации доверяют и как находят своего профессионала-юриста? Эти и другие вопросы были зада- 
ны в ноябре 2017 г. в ходе соџиологического исследования методом уличного интервью жителям г. Саратова.

В ходе исследования «Правовые практики жителей г. Саратова» собрана информация у 547 респондентов. Выборка конструировалась по целевому принципу: респонденты опрашивались на улице вблизи с такими объектами соџиального значения, как суды и мировые судьи, МФЦ, Регпалата, комитет социальной защиты населения, торговые центры, что позволило с большей вероятностью выйти на слои населения, столкнувшиеся с определенными юриАическими проблемами. Среди опрошенных преобладали женщины (55,6\%), мужкин - 44,4\%. Согласно статистическим данным, на 1 января 2015 г. в г. Саратове проживали 55,4\% женщин и 44,6\% мужчин, что практически полностью соответствует гендерным параметрам выборочной совокупности.

Среди респондентов по возрасту наблюдается некоторый перекос в сторону преАставителей молодежи: на Аолю респондентов от 18 до 35 мет при-

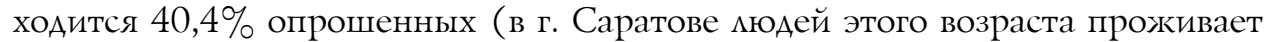
$35,2 \%$ ), тогда как пенсионного возраста (56 кет и старше) - 30,3\% (в г. Саратове - 31,4\%) [7], что не в полной мере соответствует параметрам генерацьной совокупности. ОАнако выявленные отклонения, с учетом используемых при отборе респондентов методов, вполне ожидаемы и не оказывают заметного негативного вцияния на полученные резуцьтаты. Аоля опрошенных с уровнем образования «общее среднее и ниже» составияа 9,7\%, со среАним спеџиальным - 33,5\%, самой многочисленной оказалась группа респондентов с неполным высшим/высшим профессиональным образованием (54,8\%). Чаще всего в зону внимания интервьюеров попадали наемные работники (45,9\% всей совокупности) и пенсионеры $(22,7 \%)$. Среди респондентов оказались и безработные / Аомохозяева (9,5\%), студенты $(8,6 \%)$, преАприниматели (6,8\%). Такие категории населения, как руководитель, замещающий выборную должность, руководитель по найму и военнослужащий, встречались крайне реАко и в совокупности не превысили $5 \%$.

На этапе разработки инструментария исследования был очерчен круг ряда проблем правового характера, с которым население города предположительно чаще всего сталкивается, а именно низкое качество товаров в сферах торговци и услуг, вопросы организации и оплаты труда, проблемы аварийного жкицья и решения семейно-имущественных споров. Опрос респондентов показал, что наиболее распространенной проблемой оказалось нарушение прав потребитемя: треть опрошенных сообщили, что в такую ситуаџию они попали в текущем году, около четверти опрошенных - в течение двух последних мет и ранее. Аишь 37,7\% респондентов с такой проблемой никогда не сталкивались. Второй по степени значимости оказалась проблема аварийного жкицья: 17,9\% респондентов определици ее как актуальную Аля себя. Третьими по распространенности оказацись трудовые споры. Пережили этот опыт недавно 6,6\% опрошенных, давно - 8,2\%. Более трети респондентов $(39,7 \%)$ считают, что могут столкнуться с этой проблемой в будущем, примерно столько же (38\%), что не столкнутся с ней ни при каких обстоятельствах. Наконец, проблема

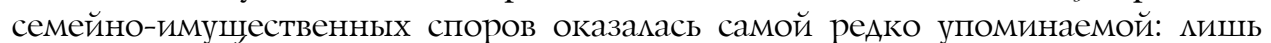
2,4\% респондентов столкнулись с ней в текущем году, 5,9\% - в течение пос- 
медних двух мет и более. Никогда с ней не сталкивалась подавляющая часть опрошенных $(89,2 \%)$.

Более глубокий статистический анализ данных показал наличие зависимости межАУ опытом столкновения с той ици иной пробцемой и степенью эффективности ее решения. Отвечая на вопрос о результатах решения той ими иной проблемы, более половины опрошенных $(54,1 \%)$ признали ее решенной. Около четверти респондентов $(26,8 \%)$ Ааже не приступали к ее решению; $11 \%$ предприняли некоторые попытки ее решения, но проблема сохранилась; $8 \%$ находятся в проџессе решения проблемы.

Сравнение ответов респондентов в зависимости от того, с какой проблемой правового характера они столкнулись, показало, что наиболее часто откладывают решение проблемы «в Аолгий ящик» респонденты в ситуации аварийного жилья (30,4\% от общего числа имеющих соответствуюший опыт), затем - респонденты, столкнувшиеся с нарушением прав потребитемя (23,2\%), нарушением прав в трудовой сфере $(12,9 \%)$, с проблемой решения семейно-имущественных споров $(4,5 \%)$. Таким образом, налицо значительный разброс показателей: от 5 до 30\%, что позволяет разделить изучаемые проблемы на «подАающиеся» оперативному решению (семейно-имушественные споры, трудовые споры) и «не подАающиеся» (пробцема аварийного жицья), а может быть, и не требующие решения вообше (нарушение прав потребителя).

Тем не менее большая часть опрошенных все же предпринимали опредеменные попытки дяя разрешения своих проблем. Так, $19 \%$ саратовцев, принявших участие в опросе, попытались решить проблему аварийного жилья, но безуспешно; $15,9 \%$ респондентов, столкнувшихся с семейно-имушественными спорами, также потерпели фиаско; чуть меньше (13,3\%) неудачливых потребителей оказались не в состоянии решить свою проблему до конца. Самая малая доля респондентов, попытавшихся, но не сумевших решить проблему, оказалась в разряде работающих, столкнувшихся с трудовыми спорами $(8,6 \%)$. Наиболее успешно респонденты действовали в ситуации трудовых споров, а именно 67,1\% удалось полностью решить проблему. Второе место разделили семейно-имушественные споры $(56,8 \%)$ и нарушения прав потребителя $(53,9 \%)$. Среди наиболее сложно решаемых оказалась проблема аварийного жилья (разрешили ее кишь 35,4\% опрошенных).

У оказавшихся вовлеченными в семейно-имущественные споры проблема находится в проџессе разрешения у $22,7 \%$ респондентов; $15,2 \%$ саратовцев - владельцев аварийного жилья решают, но пока еще не решили свою задачу; чуть реже встречаются в выборке респонденты, вовлеченные в трудовые споры $(11,4 \%)$, которые также находятся в проџессе решения Аанной проблемы; мишь 9,5\% опрошенных столкнулись с нарушениями прав потребителя. Итак, выделенные проблемы достаточно четко можно сгруппировать на «быстро решаемые (нарушение прав потребителя и трудовые споры) и «требующие Алительного времени Аля своего решения» (проблема аварийного жилья, семейно-имущественные споры).

Резюмируя изложенное, можно следующим образом охарактеризовать рассмотренные проблемы в зависимости от того, какой опыт саратовцы получили в процессе их разрешения: 
1. Проблема нарушения прав потребителя относится к категории «откладываемых» предположительно из-за невысокой значимости, поскольку не представляет трудности в проџессе ее решения.

2. Проблема аварийного жилья также относится к категории «откладываемых», но по причине, связанной с особой сложностью решения, и, как следствие, ее решение требует довольно Алительного ожидания.

3. Трудовые споры являются оперативно решаемой проблемой, при этом характеризуются низким уровнем сложности в решении, высокой степенью результативности и относительной быстротой.

4. Семейно-имущественные споры относятся к категории «требующих неотможного решения», вероятно, в связи с высокой значимостью этой проблемы в глазах населения. Проблемы этой категории характеризуются определенными трудностями решения, но значительная часть опрошенных достигает успеха.

В целом горожане достаточно часто сталкиваются с нарушением или неисполнением законов: только треть респондентов (34,9\%) не имеют такого жизненного опыта, что указывает на распространение различного типа правонарушений и низкий уровень общей правовой культуры. Аیя более глубокого понимания сути проблемы имеет смысм напомнить о понятии аномии, введенном в научный оборот французским соџиологом Э. Аюркгеймом, обрисовавшим особое состояние общества, характеризующегося разложением, дезинтеграцией и распадом системы устоявшихся ценностей и норм, ранее поддерживавшей традиционный общественный порядок, по причине ее несоответствия новым сформулированным и принятым государством идеалам [8] . Аругими словами, Э. Аюркгейм описывац состояние аномии как результат полного отсутствия норм. В российском варианте аномия явцяется результатом развития Аругой ситуации: с одной стороны, имеется довольно значительный корпус законов и подзаконных актов, с другой - фактически эти законы и подзаконные акты не явмяются обязательными дия исполнения. В результате неисполнение и даже нарушение законов становится обычной практикой, реализующейся на всех уровнях общественной жизни.

Как же действуют жители г. Саратова, столкнувшись с фактом неисполнения или нарушения закона? Из 65\% респондентов, имеющих такой опыт, 27,4\% предпочитают обратиться за квалифиџированной помошью к юристам. Таким образом, существует довольно заметная доля гражкан (чуть более четверти всех опрошенных), готовых решать свои проблемы в правовом поле, что можно рассматривать как свидетельство постепенно формируюшегося пространства правовой культуры. Вместе с тем практически такая же домя опрошенных (26,3\%) в ситуации нарушения закона предпочитают действовать самостоятельно, то есть обрашаться к неправовым практикам дмя решения проблем, $8 \%$ саратовцев вовсе отказываются от ее решения, что указывает на сохранение высокого уровня недоверия и даже правового нигилизма к формирующейся системе права.

Но даже среди респондентов, готовых действовать в правовом пространстве, отмечаются признаки недоверия к формальным соџиальным институтам: в проџессе поиска квалифицированного юриста чуть более половины респондентов $(53,1 \%)$ обрашаются за рекомендациями к Арузьям, родным, близким; 32,2\% ориентируются на личных знакомых или руководствуются 
мичным опытом. Парадоксально, но столь эффективный инструмент в плане предложения клиентам самых разных услуг, как реклама, показал себя в цецом малоэффективным: таким способом в СМИ ищут юриста 27,4\% опрошенных, с помощью наружной рекламы - лишь $4,2 \%$.

Основными проблемами, побуждающими население обратиться за квамифиџированной юридической помощью, связаны с недвижимостью (в том числе с аварийным жильем) - их отметили 47,7\% опрошенных; денежными выплатами - 24,3\% и трудовыми вопросами $-21,4 \%$. В семейно-брачную сферу респонденты не столь охотно допускают «посторонних». Относительно редко указывались и проблемы с кичным бизнесом, что можно объяснить немногочисленностью группы предпринимателей в выборке.

На вопрос о том, какие проблемы способны подтолкнуть их к обращению за профессиональной юридической помощью, респонденты могли дать собственные ответы, и часть опрошенных воспользовалась Аанной возможностью. Чаше всего респонденты называли проблемы, связанные с нарушением прав потребителя и с работой ЖКХ (по 1,5\%, или по 8 респондентов). Несколько реже назывались уголовное преступление $(1,1 \%$, или 6 респондентов) и некачественное оказание медищинских ускуг (0,6\%, или 3 респондента). Ни при каких обстоятельствах обрашаться к юристу не будут мишь $12 \%$ опрошенных.

Сравнение проблемных полей, предможенных респондентам как побудительные причины для обращения к квалифицированной юридической помощи, по степени их актуальности Аля самих опрошенных выявимо на редкость однообразное колебание в ответах опрошенных: от четверти Ао пятой части респондентов оценивают упомянутые причины как актуальные на настоящий момент; от 5 до 9\% - как предположительно актуальные в ближкайшее время; от 65 до 85\% - как неактуальные. Уровень актуальности ответов, предможенных самими респондентами, размичается в большей степени. Наиболее актуальной оказалась проблема, связанная с работой ЖКХ: из шести человек, упомянувших ее, пять охарактеризовали как несомненно актуальную, один - как вероятно актуальную.

Проблемы, связанные с уголовным преступиением, нарушением прав потребителя и оказанием медицинских услуг, можно определить как актуальные в средней степени. Из шести человек, назвавших проблему, связанную с уголовным преступцением, три определили ее как несомненно актуальную, один - как вероятно актуальную; из шести человек, назвавших проблему, связанную с нарушением прав потребителя, Ава отметили ее как актуальную, один - как вероятно актуальную. Проблему, связанную с оказанием медицинских услуг, определили как актуальную, вероятно актуальную и неактуальную - по одному человеку соответственно.

В целом рассмотрение проблем, с которыми сталкиваются респонденты, в качестве стимулов обращения к юридической помощи позвомяет обнаружить некие «точки роста» правовой кумьтуры и правового сознания у населения. В первую очередь это та часть горожан, которая сталкивается с проблемами в сферах недвижимости и денежных выплат, другими словами, имеющая определенные ресурсы, но при этом наталкивающаяся на серьезные формальные преграды, мешающие распоряжаться ими.

Таким образом, объективная потребность в правовой помощи и защите у саратовцев высока, поскольку подавмяющее большинство опрошенных стал- 
кивается в своей жизни с фактами неисполнения и даже прямого нарушения законов, Аично затрагивающих их. Аостаточно часто саратовцы сталкиваются с ситуациями нарушения прав потребителя, реже - с проблемами аварийного жимья, нарушений в трудовой сфере, семейно-имущественными спорами. Аишь четверть опрошенных продемонстрировала готовность обратиться к квалифицированным юристам дмя решения подобных проблем, а чуть более десятой части опрошенных не будут обращаться за профессиональной юриАической помощью ни при каких обстоятельствах. Наиболее попумярным у респондентов был ответ, связанный с самостоятельным решением проблемы правового характера. Это, с одной стороны, указывает на появление некой совокупности Аюдей, обладающих вполне сформированным правовым знанием, а с Аругой - на все еше распространенное недоверие к правовым способам решения проблем и даже правовой нигилизм. Эмпирические Аанные 2017 г. поАтверждают вывод М.Б. Смоленского, еще в 2003 г. отметившего, что «правовая культура в России характеризуется преимущественно неправовым характером социальных практик и нигилистическим отношением к праву» [9] .

Тем не менее горожкане постепенно определяют круг пробцем, которые, по их мнению, мучше решать в правовом ключе. Иссмедование выявияо, что их решения находятся в зависимости от соџиального статуса, уровня образования, возраста и пола респондентов. В целом исследование саратовских правовых практик позволило определить и интегральный образ горожанина - потенциального кАиента юридических служб. Это преимущественно женщина 33-42 кет, наемный работник с высшим образованием, носитель проблемных вопросов потребительского характера, связанных с недвижимостью или семейно-имущественными проблемами.

\section{Библиографический список}

1. Куликова А.В. Проблемы формирования правовой культуры населения России : автореф. дис. ... канд. социол. наук. Н. Новгород, 2005.

2. Петров B.P. Деформация правосознания граждан России: (проблемы теории и практики): автореф. дис. ... канд. юрид. наук. Н. Новгород, 2000.

3. Карпушкин С.И. Формирование гражданской и правовой культуры молодежи: автореф. дис. ... канд. филос. наук. М., 1999.

4. Аллаярова Э.М. Правовая информированность населения в условиях современного российского общества // Концепт: научно-методический электронный журнал. 2016. Т. 11. C. 2406-2410. URL: http://e-koncept.ru/2016/86511.htm

5. Основы государственной политики Российской Федерации в сфере развития правовой грамотности и правосознания граждан. Утв. Президентом РФ 28 апр. 2011 г. № Пр-1168) // Российская газета. 2011. № 151.

6. Михайлов А.Е. Правовая жизнь современной России: проблемы теории и практики: автореф. дис. ... канд. юрид. наук. Саратов, 2004.

7. Возрастно-половой состав населения города Саратова: статистический бюллетень / Территориальный орган Федеральной службы государственной статистики по Саратовской области. Саратов, 2015.

8. Дюркгейм Э. О разделении общественного труда. М., 1996.

9. Смоленский М.Б. Правовая культура как элемент социокультурного пространства: перспективы становления в современной России: автореф. дис. ... д-ра социол. наук. Ростов н/Д, 2003. 